\title{
CINÉTICA DE ADSORÇÃO DO CORANTE REATIVO PRETO 5 APLICANDO ADSORVENTE COMERCIAL E PIROLISADO DE RETALHOS DE TECIDO
}

\author{
R. F. dos SANTOS ${ }^{1}$, J. CORREIA ${ }^{2}$, R. C. S. C. VALLE ${ }^{1}$, C. R. L de AGUIAR ${ }^{1}$, e J. A. B. \\ VALLE $^{1}$ \\ ${ }^{1}$ Universidade Federal de Santa Catarina, Curso de Engenharia Têxtil \\ ${ }^{2}$ Universidade Federal de Santa Catarina, Curso de Engenharia Química \\ E-mail para contato: renan.felinto93@gmail.com
}

\begin{abstract}
RESUMO - Diferentes métodos são aplicados como alternativa a remoção de corantes, melhorando o tratamento de efluentes industriais. Sendo assim, a adsorção é um processo que vem se mostrando promissor como mecanismo de tratamento de efluentes. Este trabalho teve como objetivo analisar a aplicação de dois diferentes tipos de adsorvente, carvão comercial e adsorvente pirolisado, na adsorção de corante reativo preto 5 , durante 24 horas de testes em temperatura ambiente $\left(25^{\circ} \mathrm{C}\right)$ e em $\mathrm{pH} 3,0$. Para o ajuste de dados experimentais, foram utilizados os modelos cinéticos de pseudo primeira e pseudo segunda ordem. Nos testes avaliados a concentração de corante no adsorvente foi de $36,8 \%$ para o carvão comercial, sendo da mesma ordem de grandeza da concentração removida pelo carvão pirolisado $(34,6 \%)$. O adsorvente pirolisado mostrou-se eficiente como material adsorvente de baixo custo na remoção do corante Reativo Preto 5, com altas taxas de adsorção.
\end{abstract}

\section{INTRODUÇÃO}

O setor têxtil é caracterizado pela utilização de um alto volume de recursos hídricos em seus processos fabris, sendo, basicamente dividida em fiação, tecelagem e beneficiamento, cada qual responsável por um objetivo para a constituição do artefato têxtil final. O processo de beneficiamento é a etapa que mais se utiliza de recurso hídrico para incorporação de características físicas e químicas aos artigos têxteis. Inúmeras são as substâncias utilizadas para o beneficiamento de tecidos, o que resulta em um efluente com alto índice de variabilidade, já que cada fibra necessita de diferentes químicos aplicados a essa etapa para se chegar às características desejadas. Um processo de tingimento consome mais de $100 \mathrm{~L}$ de água por quilo de material processado, sendo $80 \%$ deste volume descartado como efluente (Vajnhandl e Valh, 2014).

De fato e conforme citado pelo Conselho Nacional do Meio Ambiente (CONAMA, 1997), o setor têxtil possui grau médio de degradação ambiental. Sendo assim, com a grande quantidade de efluente gerado, as indústrias precisam se adequar e melhorar seus processos de tratamento de efluente constantemente, buscando aumentar a eficiência e remoção de substâncias degradantes do residual líquido, antes de devolver esse montante ao meio ambiente. Para tanto, as empresas devem seguir leis que ditam os parâmetros de qualidade 
mínimos do efluente que irá retornar aos rios e lagos de onde retiraram a água utilizada na indústria.

Dentre os produtos utilizados, os corantes são as substâncias de maior grau de dificuldade de remoção do efluente, já que são amplamente utilizados pelo fato que cada tipo de fibra necessita de corantes com características próprias e bem definidas (Guaratini e Zanoni, 2000), para que o processo de tingimento seja executado corretamente. Sendo assim, a composição do efluente é definida diretamente a partir do artefato têxtil em produção.

Portanto, para atender as regulamentações as empresas dispõem, normalmente, da combinação de processos físicos, químicos e biológicos convencionais para tratar o residual líquido do processo fabril. Entretanto, com o apelo ecológico em constante crescimento, as indústrias devem se adequar e aplicar novos processos em suas plantas. Entre todos os estudos e pesquisas, pode-se destacar a adsorção como um processo promissor, sobretudo, de baixo custo e altamente eficiente (Dallago et al., 2005), o que se torna um grande atrativo para as indústrias.

A adsorção é um processo no qual algumas características do adsorvente devem ser levadas em consideração para que o processo ocorra de forma eficiente, como citado por Cardoso et. al, (2011), fatores como superfície do adsorvente, $\mathrm{pH}$ e tempo de contato influenciam neste método.

Neste sentido, este trabalho teve como objetivo analisar o processo de adsorção através da utilização de dois diferentes adsorventes: carvão comercial e outro obtido através da ativação química e pirólise de retalhos de tecidos provenientes do processo produtivo de uma indústria têxtil, na remoção de corante reativo preto 5.

\section{MATERIAIS E MÉTODOS}

Os experimentos foram realizados no Laboratório de Transferência de Massa (Labmassa) do Departamento de Engenharia Química da Universidade Federal de Santa Catarina e no Laboratório de Meio Ambiente (LabMam) da Universidade Federal de Santa Catarina Centro de Blumenau.

\subsection{Materiais}

Os adsorventes utilizados para a realização dos testes foram: carvão comercial da empresa Carbomafra, com granulometria 0,55-0,70 $\mathrm{mm}$ e adsorvente produzido a partir da ativação química e posterior pirólise de resíduos oriundos da manufatura têxtil de uma indústria localizada no munícipio de Blumenau - SC. Para a produção da solução sintética empregou-se o corante preto reativo Remazol N Gran 150\% C.I Reactive Black 5 da empresa Dystar. Para o ajuste de pH 3 utilizou-se solução de ácido acético.

\subsection{Ativação Química}

Utilizando carbonato de potássio $\left(\mathrm{K}_{2} \mathrm{CO}_{3}\right)$, o resíduo têxtil foi submetido ao processo de ativação química. Este procedimento foi adaptado dos trabalhos de Brum (2010) e Gurten et 
al., (2012). Em um béquer, misturou-se $30 \mathrm{~g}$ da amostra precursora com $\mathrm{K}_{2} \mathrm{CO}_{3}$ anidro e água destilada na proporção mássica de 1:1:6 (amostra: $\mathrm{K}_{2} \mathrm{CO}_{3}$ :água). A mistura foi seca durante $24 \mathrm{~h}$ a $110^{\circ} \mathrm{C}$.

\subsection{Pirólise}

O processo de pirólise foi realizado utilizando $30 \mathrm{~g}$ de amostra (previamente ativada com $\mathrm{K}_{2} \mathrm{CO}_{3}$ ) que foram adicionadas a um reator, e este, posteriormente colocado em uma mufla. Por sua vez, a mufla é acoplada a um dispositivo (condensador) que irá condensar as impurezas que saem pelo orifício superior da mesma. O condensador é seguido por um borbulhador responsável pela lavagem dos gases, contendo solução $1 \mathrm{M}$ de $\mathrm{NaOH}$.

Uma trompa de vácuo foi utilizada para manter o processo a $3 \mathrm{cmHg}$ de vácuo, sendo controlado manualmente e observado através de um manômetro de mercúrio tipo tubo em U. A Figura 1 apresenta o esquema do processo de pirólise. A mufla foi ajustada para trabalhar com aquecimento a uma taxa de $10^{\circ} \mathrm{C} / \mathrm{min}$ até atingir a temperatura de $500{ }^{\circ} \mathrm{C}$ e mantendo essa temperatura durante 70 minutos, sendo o tempo total de pirólise da amostra (Sonai et al., 2016).

Figura 1 - Esquema do processo de pirólise: (a) mufla, (b) condensador, (c) coletor de condensado, (d) frasco borbulhador, (e) manômetro e (f) trompa de vácuo. Adaptado de Sonai et al. (2016).

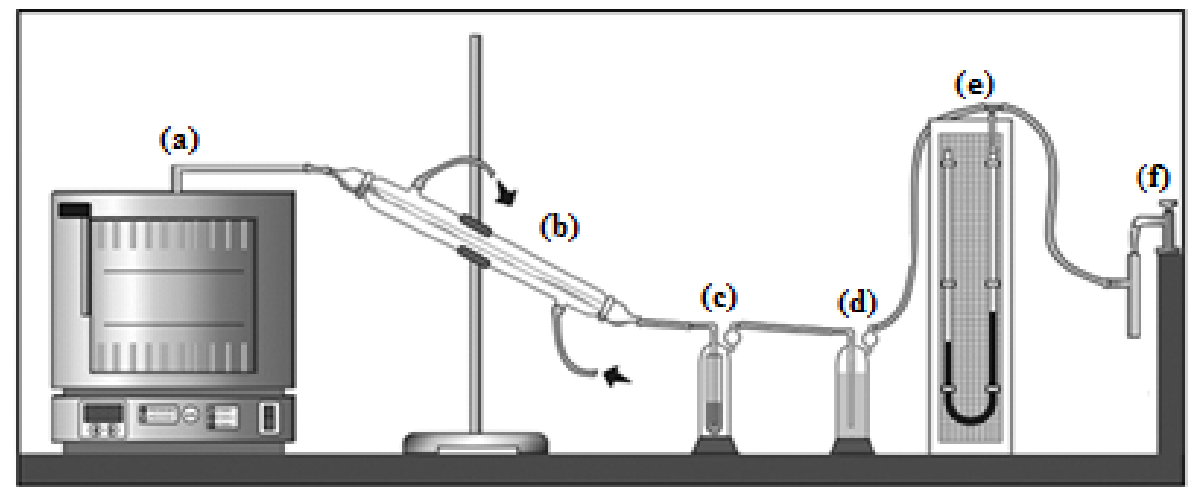

\subsection{Cinética de adsorção}

Os testes foram realizados em meio ácido, ajustado para o $\mathrm{pH} 3$. A solução inicial foi composta de $40 \mathrm{mg} / \mathrm{L}$ de corante reativo preto e $3 \mathrm{~g} / \mathrm{L}$ de adsorvente. Os testes foram realizados em temperatura ambiente, durante 24 horas utilizando um shaker para frascos de erlenmeyer de $125 \mathrm{~mL}$, com agitação de $110 \mathrm{rpm}$, empregando $50 \mathrm{~mL}$ de volume útil com solução sintética de corante, adsorvente e água destilada. Alíquotas de $5 \mathrm{~mL}$ das amostras foram retiradas em tempo inicial, 15, 30, 60, 120, 180, 270, 360, 480, 600 e 1440 minutos, sendo posteriormente analisadas em espectrofotômetro da marca Micronal modelo AJX 1900 utilizando o comprimento de onda de $598 \mathrm{~nm}$. A partir dos resultados obtidos foram construídas as cinéticas da concentração de corante no adsorvente a partir da Equação (1). 


$$
q=(C o-C) \times V / m
$$

Onde, $C_{o}\left(m g . L^{-1}\right)$ representa a concentração inicial de corante na solução, $C\left(m g . L^{-1}\right)$ é a concentração de corante na solução, V (L) e m (g) são, respectivamente, o volume de solução e a massa de adsorvente utilizado (Chiu e $\mathrm{Ng}, 2012$ ).

A capacidade de adsorção de ambos os carvões foi avaliada empregando os modelos de pseudo primeira e segunda ordem para o ajuste das curvas cinéticas, apresentado pelas Equações (2) e (3), respectivamente. O modelo de pseudo primeira ordem considera a difusão no poro a única etapa limitante do processo, enquanto o modelo de pseudo segunda ordem considera que a adsorção na superfície é a etapa lenta do processo. O ajuste dos modelos foi obtido por regressão não linear, utilizando o programa QtiPlot 0.9.9.6.

$$
\begin{aligned}
& q=q_{e}\left(1-e^{-k_{1} \cdot t}\right) \\
& q=\frac{k_{2} \cdot q_{e}{ }^{2} \cdot t}{1+k_{2} \cdot q_{e} \cdot t}
\end{aligned}
$$

Onde, $\mathrm{q}_{\mathrm{e}}\left(\mathrm{mg} \cdot \mathrm{g}^{-1}\right)$ representa a quantidade adsorvida de soluto no equilíbrio, $\mathrm{k}_{1}\left(\mathrm{~min}^{-1}\right)$ é a constante de adsorção de pseudo-primeira ordem, $\mathrm{k}_{2}\left(\mathrm{~g} \cdot \mathrm{mg}^{-1} \cdot \mathrm{min}^{-1}\right)$ é a constante de adsorção de pseudo-segunda ordem e t (min) é o tempo de adsorção (Ho e Mckay, 1999).

\section{RESULTADOS E DISCUSSÕES}

A concentração final de corante foi de $25,17 \mathrm{mg} . \mathrm{L}^{-1}$ e $25,95 \mathrm{mg} . \mathrm{L}^{-1}$, equivalente a $36,8 \%$ e $34,6 \%$ de remoção do corante em solução aplicando adsorvente comercial e pirolisado, respectivamente. Por isso, pode-se afirmar que os dois adsorventes utilizados removeram da solução aproximadamente a mesma quantidade de corante após 24 horas de adsorção.

Para uma melhor comparação de resultados entre os carvões utilizados os modelos cinéticos de pseudo primeira e pseudo segunda ordem foram aplicados para o ajuste de dados. Conforme os valores das regressões obtidos podem ser observados na Tabela 1 é possível constatar que o modelo de pseudo primeira ordem como o mais adequado para o ajuste de dados do processo aplicando adsorvente pirolisado, já para o processo com carvão comercial os resultados obtidos são mais adequados ao modelo de pseudo segunda ordem.

Tabela 1 - Ajuste dos dados experimentais aos modelos cinéticos.

\begin{tabular}{ccccccc}
\hline & \multicolumn{3}{c}{ Pseudo primeira ordem } & \multicolumn{3}{c}{ Pseudo segunda ordem } \\
\hline $\begin{array}{l}\text { Tipo de } \\
\text { carvão }\end{array}$ & qe $\left(\mathrm{mg} \cdot \mathrm{g}^{-1}\right)$ & $\mathrm{k}_{1} \cdot 10^{-3}\left(\mathrm{~min}^{-1}\right)$ & $\mathrm{R}^{2}$ & $\mathrm{qe}\left(\mathrm{mg} \cdot \mathrm{g}^{-1}\right)$ & $\mathrm{k}_{2 .} \cdot 10^{-4}\left(\mathrm{mg} \cdot \mathrm{g}^{-1} \cdot \mathrm{min}^{-1}\right)$ & $\mathrm{R}^{2}$ \\
\hline $\begin{array}{c}\text { Comercial } \\
\text { Pirolisado }\end{array}$ & 5,26 & 1,49 & 0,80 & 6,58 & 2,28 & 0,83 \\
\hline
\end{tabular}

A Figura 2 apresenta cinética de adsorção relacionando a quantidade de corante adsorvida no sólido, com o ajuste dos dois modelos cinéticos. Observa-se que o carvão 
comercial apresentou capacidade levemente superior, entretanto necessitou de um prazo muito maior para adsorção. As constantes cinéticas apresentadas na Tabela 1, relativas a velocidade de adsorção, foram notavelmente superiores para o adsorvente pirolisado.

A curva do carvão comercial não atingiu equilíbrio no final da adsorção. Após 24 horas foi adsorvido 4,891 mg.g ${ }^{-1}$, enquanto que a capacidade de adsorção no equilíbrio, é de 5,263 $\mathrm{mg} \cdot \mathrm{g}^{-1}$ e $6,587 \mathrm{mg} \cdot \mathrm{g}^{-1}$, respectivamente para os modelos de pseudo primeira e pseudo segunda ordem.

Os modelos não apresentaram bons ajustes aos dados experimentais para o carvão comercial, provavelmente em virtude da cinética não ter alcançado o equilíbrio. Para o adsorvente pirolisado ambos os modelos apresentaram bons ajustes, indicando que pelo menos duas etapas controlam a velocidade de adsorção: a difusão no poro e adsorção na superfície do adsorvente proposta pelos modelos de pseudo primeira e segunda ordem, respectivamente.

Figura 2 - Cinética de adsorção (em função da quantidade de corante adsorvida no sólido) para o corante preto reativo 5 para o carvão comercial e adsorvente pirolisado.

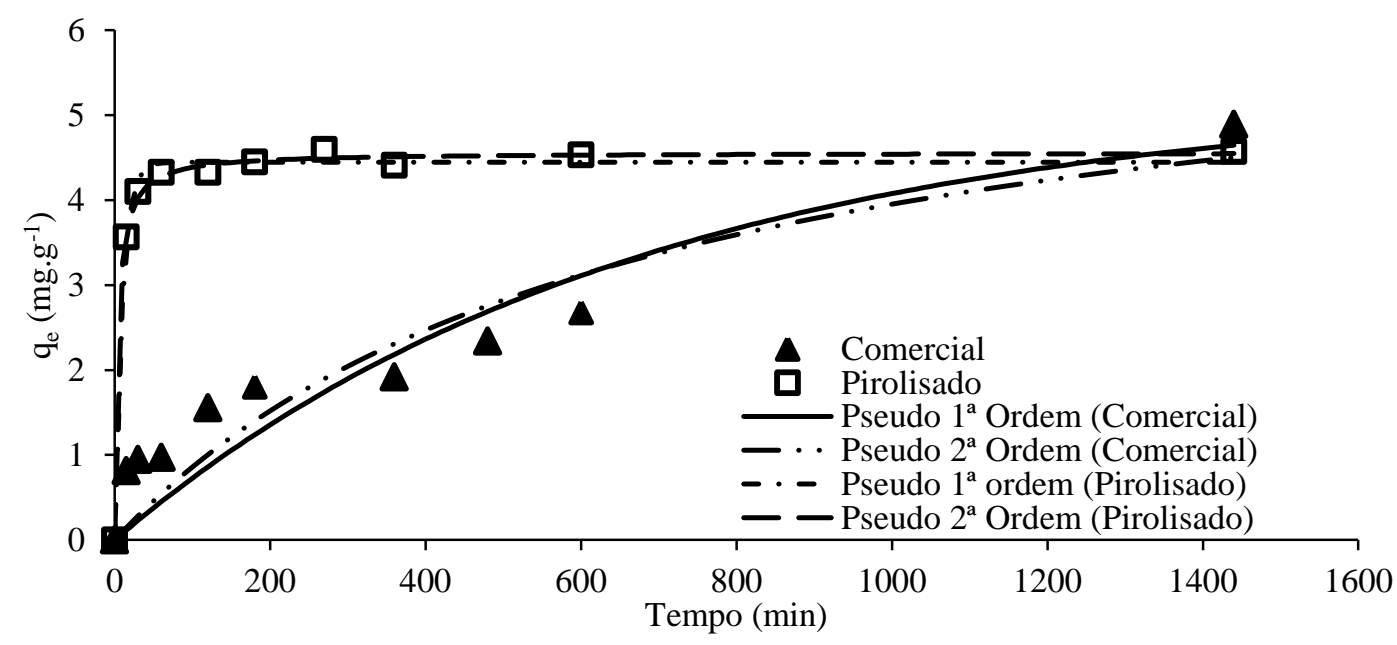

\section{CONCLUSÃO}

Os estudos cinéticos indicaram que é necessário um prazo de adsorção superior a 24 horas para alcançar o equilibro, de forma a obter uma curva cinética completa e melhores ajustes aos modelos. Para o adsorvente pirolisado o equilíbrio é atingido em menos de 2 horas, a velocidade de adsorção para o adsorvente pirolisado é controlada por duas etapas: a difusão no poro e adsorção na superfície do adsorvente.

Embora o carvão comercial tenha uma maior capacidade de adsorção, o adsorvente pirolisado apresentou uma velocidade de adsorção muito maior, o que representa economia no tempo e nas dimensões de equipamentos em escala industrial.

$\mathrm{O}$ adsorvente pirolisado mostrou-se eficiente como material adsorvente de baixo custo na remoção do corante Preto Reativo 5 em solução aquosa, quando empregado no processo de 


\section{Congresso Brasileiro de Engenharia Química \\ em Iniciação Científica \\ UFSCar - São Carlos - SP \\ 16 a 19 de Julho de 2017}

adsorção. A transformação de um rejeito poluidor em matéria-prima de um produto aplicável no tratamento de efluentes industriais, é a grande contribuição do presente estudo.

\section{REFERÊNCIAS}

BRUM, S. S. Catalisadores de zircônia sulfatada e compósitos de carvão ativado/zircônia sulfatada para produção de biodiesel e etanol. Universidade Federal de Lavras. Tese (Doutorado em Agroquímica), Lavras - MG, 2010.

CARDOSO, N. F; PINTO, R. B; LIMA, E. D; CALVETE, T.; AMAVISCA, C. V, ROYER, B.; CUNHA, M. L.; FERNANDES T. H. H.; PINTO, I. S. Remozal of remazol black B textile dye from aqueous solution by adsorption. Desalination, v. 269, p. 92-103, 2011.

CHIU, K.-L.; NG, D. H. L. Synthesis and characterization of cotton-made activated carbon fiber and its adsorption of methylene blue in water treatment. Biomass and Bioenergy, v. 46, p. 102-110, nov. 2012.

CONSELHO NACIONAL DO MEIO AMBIENTE (CONAMA). Resolução nº 237, de 19 de dezembro de 1997. Dispõe sobre as atividades ou empreendimentos sujeitos ao Licenciamento Ambiental. $1997 . \quad$ Disponível em: <http://www.mma.gov.br/port/conama/res/res97/res23797.html>. Acesso em: 05 de outubro de 2016.

DAllago, R. M., SMANiOTTO, A., OliVEIRA, L. C. A. Resíduos sólidos de curtumes como adsorventes para a remoção de corantes em meio aquoso, Quim. Nova, v. 28, n. 3, p. 433-437, 2005.

GUARATINI, C. C. I.; ZANONI, M. V. Corantes Têxteis. Quím. Nova, v. 23, n. 1, p. 71-78, 2000 .

GURTEN, I. I.; OZMAK, M.; YAGMUR, E.; AKTAS, Z. Preparation and characterisation of activated carbon from waste tea using $\mathrm{K}_{2} \mathrm{CO}_{3}$. Biomass and Bioenergy, v. 37, p. $73-$ 81, fev. 2012.

HO, Y. S.; MCKAY, G. Pseudo-second order model for sorption processes. Process Biochemistry, v. 34, n. 5, p. 451-465, 1999.

SONAI, G. G.; SOUZA, S. M. A. G. U. de; OLIVEIRA, D. de; SOUZA, A. A. U. de. The application of textile sludge adsorbents for the removal of Reactive Red 2 dye. Journal of environmental management, v. 168, p. 149-56, 1 mar. 2016.

VAJNHANDL, S. VALH, J. V. The status of water reuse in European textile sector. Journal of Environmental Management, v. 141, p. 29-35, 2014. 